\title{
The Design of the Management Platform on Sharing Specialty Teaching Resource Database
}

\author{
Wu Guohua \\ College of Education Science and Technology, Guangdong Polytechnic Normal University \\ Guangzhou, China \\ wuguohua2002@qq.com
}

\begin{abstract}
The existing education resource base has bad sharing property, and cannot dock with specialty classification, so it can be hard to meet the education demand, thus in order to solve the aforementioned problems, this paper puts forward that the construction of teaching database shall follow the principle of standardization, sharing and discipline, provides the reference standard for the construction of resource base, and designs the overall structure and systematic functional structure for the management platform of shared-type specialty teaching resource base. This platform can solve the difficulty of resource sharing, promote the resource sharing for schools within the region, and effectively meet the current teaching demand.
\end{abstract}

\section{Keywords—sharing; teaching resource base; platform}

\section{THE RISE OF PROBLEMS}

The development and utilization of information resources are the core contents of education informationization, and also the key point for the construction of higher education informatization [1]. In the recent years, in mainland China, more and more schools have built teaching resource base, and carried out the teaching practical activities based on the teaching resource base. Along with the education informatization progress being constantly promoted, some problems have occurred in the utilization of teaching resource base for our country.

\section{A. More resources, disorder and unsystematic, with bad sharing property}

Currently, many resources proclaim that they have certain $\mathrm{G}$ capacity of resources, but in fact, many resource bases are lack of clear thoughts in the construction process. For instance, some schools don't investigate and understand what kind of teaching resources are requested in the detailed teaching activities before constructing the teaching resource base, so that the resource base is merely the packing of lots of disorder and unsystematic data; although some schools have collected lots of teaching resources, but they often classify and define the resources as per the personal understanding and cognition of the developer. Thus, the network teaching resource of different universities generally creates the system of their own. Among these data bases that are in lack of unified standard, no effective communication or sharing can be realized [2].

Humanities and social science research project of Ministry of Education(14YJC880085); Foundation of Guangdong Educational Committee during the Twelfth Five-year Plan Period(2013JK100);Foundation for Distinguished Young Talents in Higher Education of

Guangdong(2013WYM_0049);Foundation of Guangdong Polytechnic Normal University(12SKY18).

\section{B. The resource base doesn't dock with the specialty classification, and can be hard to effectively meet the teaching demand}

Except the issue of standardization, few of the currently used resource bases will consider the issue of specialty classification in the construction process, thus after building the resource base, the teachers and students don't know how to use these resources, or use these resources to solve which aspect of issues. In other words, when using the resource base, it can be inconvenient for the teachers and students to find resources, or intensively retrieve as per specialties, and lots of time will be consumed in data analysis, which will influence the enthusiasm for the teachers and students to use the resource base, cause the decrease of resource base using efficiency, and the failure in fully reflecting the function of resource base promotion teaching.

The aforementioned issues are the two highlighted issues occurred in the application process of teaching resource base for our country. The essential reason for causing these issues is that the construction of resource base doesn't follow certain principles.

Thus, to effectively solve the aforementioned issue, it is necessary to pay attention to the aspects of standardization and specialty in the process of building the teaching resource base. Moreover, the standard and specialty teaching resource base shall be fully considered, and then take specialty as the organization guiding principle, realize stronger guarantee in quality, efficiency, sustainable development and other aspects, fully play the advantages of resource sharing, and avoid repeated construction work.

\section{CONSTRUCTION PRINCIPLE OF TEACHING RESOURCE BASE [3]}

\section{A. Principle of standardization}

The work guidance for the resource construction shall be conducted as per the Technical Specifications for the Construction of Modern Remote Education Resources, the Technical Specifications for the Construction of Education Resources, and other standards published by the Ministry of Education, and ensure that education resource construction has relatively complete and systematic technical specifications. 


\section{B. “Opening, joint construction and sharing” principle}

Opening refers to the organization of resources adopting relatively convenient modification mode; joint construction refers to mobilizing the teachers within the region; sharing refers to effectively organizing the resources collected by teachers, and then providing the free use of resources to teachers of the entire district.

\section{Principle of discipline}

The construction of resource base must possess disciplinarily, and closely combine with the disciplinary knowledge. In the construction process of teaching resource base, it is requested to consider the discipline property of resources, and then conduct resource classification and construction as per the characteristics of disciplinary knowledge, and organize the requested resources through closely centering on the disciplinary knowledge points, and the resources can directly support teaching, and facilitate the teachers to conveniently and fast find out the requested education teaching resources, so as to realize teaching optimization.

As per the aforementioned principle, this paper has designed the management platform for the shared-type specialty teaching resource base considering the problems put forward above.

\section{DESIGN SCHEME}

\section{A. Design thought}

The construction of resource base must be consistent with the specialty training plan, and the overall situation shall meet the specialty training objective, which requests that each subbase in the resource base must be organized and built through directly or indirectly centering on the specialty cultivation objective [4]. The management platform of shared-type specialty teaching resource base adopts standard design, takes the specialties as the center to build and display resources, and meanwhile, adopts the mode of school franchise mode to realize the regional teaching resource sharing.

\section{B. Reference standard}

As what mentioned above, the construction of resource base must follow the principle of standardization. The management platform designed in the paper is based on the following standards:



Fig. 1. Reference Standard for the Shared-type Specialty Teaching Resource Base

(1) Sharing standard: normalize the data and system framework, to promote sharing, including the reference model for sharable textbook object: SCORM 2004 3rd Edition, 2006 and the technical specification CELTS-41 for education resource construction and the resource framework structure construction standard [5], of which the resource framework structure construction standard mainly includes CELTS-1 system framework and reference model specification, CELTS3 learning object metadata specifications, CELTS-10 practice/test interoperation specification, CELTS-17 platform and media standard citation standard, CELTS-20 computer teaching management specification, etc.

(2) Data standard: normalize the resource data, including the resource attribute description standard and user attribute description standard. The resource attribute description standard includes GB/T13745-1992 discipline classification and code, GB/T 13959-1992 document format classification and code compilation mode, GB/T16835-1997 undergraduate of higher education institutions, name code of specialties in junior colleges, China book data classification mode (the 4th Edition), etc.

The user attribute description standard includes GB/T 2261-1980 human gender code, GB/T 4658-1984 cultural degree code, GB/T 6864-1986 PRC academic degree code, GB/T 8561-1988 specialty and technical post code, and GB/T 6565-1999 specialty classification and code.

(3) Resource quality standard: control the in-warehouse resources regarding this, and ensure that only qualified resources can be collected into the resource base.

(4) Resource evaluation standard: evaluate the resources shared by each franchised school. 


\section{Overall structure}

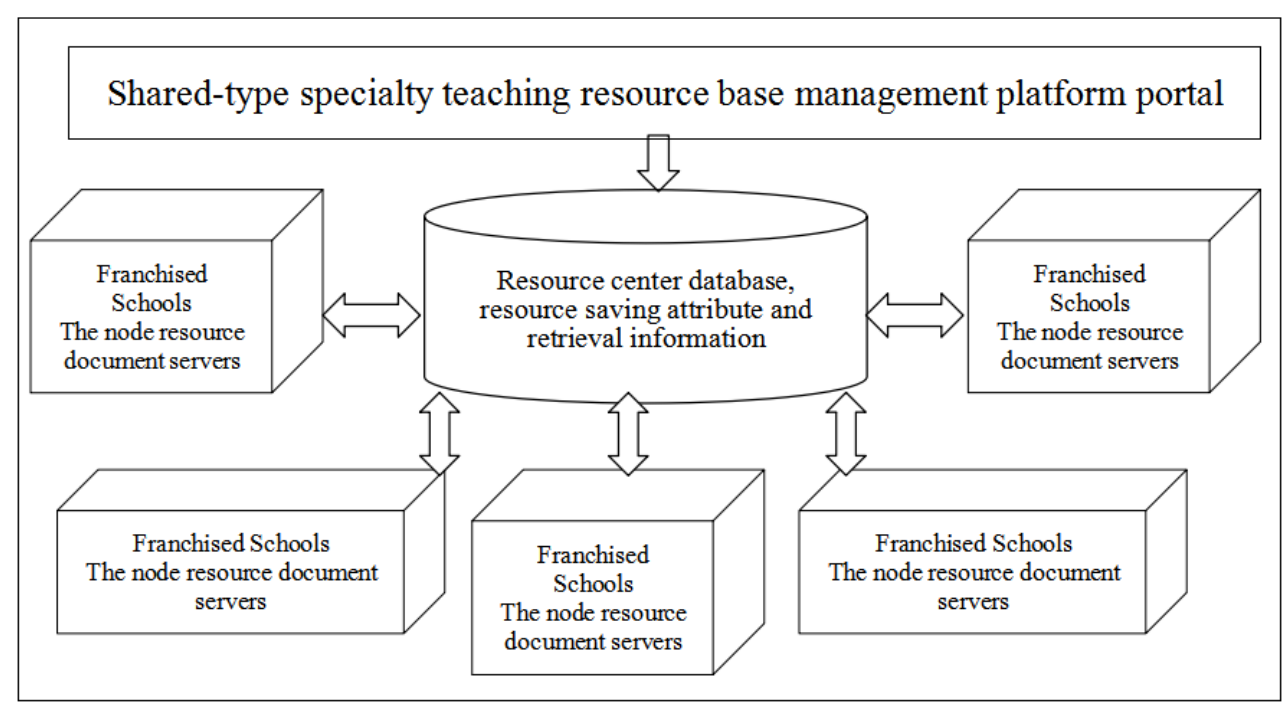

Fig. 2. The Overall Structure for the Management Platform of Shared-typed Specialty Teaching Resource Base

The resource center database stores the resource metadata information and retrieval information, and the detailed resources are stored in the node resource document servers of franchised schools. The users can retrieve resources in the resource center database of platform portal, and then operate the detailed resources in the node resource document servers of franchised schools, so as to realize the fast and intensive retrieval of resources, alleviate the load of platform portal server, and ensure the speed of response.

Each franchised school can set several node resource document servers, and also share one node resource document server with several franchised schools. The franchised school has complete control right for the resources of the affiliated node resource document servers.

The specialty teaching resource base adopts "schoolspecialty-sub-base-specific resources" four-layer management method. Firstly, it will create franchised schools on the management platform, and one franchised school can create several specialties, one specialty can create several sublibraries, which will include the detailed resources. Specialties are the bound for the contact of school and society, the key link for schools to adapt to the market, and also the concentrated reflection of school running level and layer. The shared-type specialty teaching resource library takes the specialties as the center, to build and display resources. Each specialty is a site, and it uses the mode of independent sites to display the specialties and resources.

\section{CONTENTS STRUCTURE OF SPECIALTY TEACHING RESOURCE BASE}

The main contents of specialty teaching resource base include the complete library of specialty standard, the specialty information literature library, the special characteristic resource library, multi-media courseware database, specialty figure library, specialty video animation library, test library, and case library.

\section{THE FUNCTIONAL STRUCTURE OF SYSTEM}

The functional structure of specialty teaching resource base system is as shown in Figure 3.

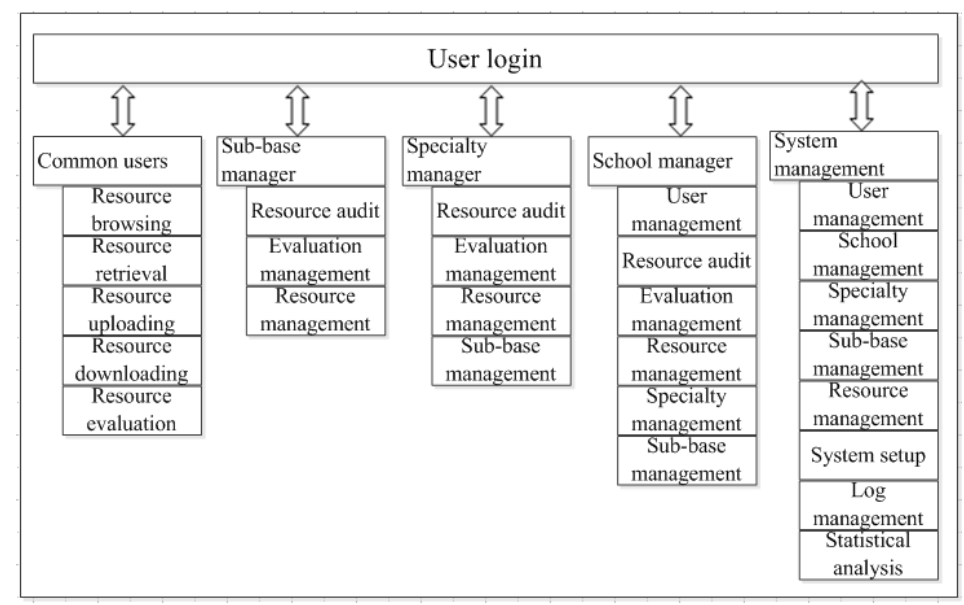

Fig. 3. The Functional Structure of Resource Base System

The specialty teaching resource base possesses the following main functions: identity authentication management; support the users to browse, retrieve, upload and download resources through the browser; support two modes, including the single document uploading and the batched documents uploading; support resource classification, resource status setup, resource editing, resource deletion and other resource management functions; support resource evaluation and management, so as to ensure the quality of in-warehouse resources; support the statistical analysis and log management of resource utilization, and confirm the using efficiency of resources; support the increase, modification, deletion and other functions of the school, specialties, and sub-libraries.

System manager: possess all the management rights; 
- School manager: possess management right for all functions of the entire school, including all the specialties and sub-bases subordinated to the school;

- Specialty manager: possess management right for the responsible specialties and the sub-base subordinated to the specialties;

- Sub-base manager: possess management right for the responsible sub-base;

- Common users: resource browsing, retrieval, uploading, downloading, and evaluation right;

\section{CONCLUSION}

This paper has designed the management platform of shared-type specialty teaching resource base considering the existing problems in the construction of the current teaching resource base, and on the basis of standardization and specialty, and can solve the difficulty of resource sharing, promote the resource sharing for schools within the region, promote the using efficiency, and effectively meet the current teaching demand.

\section{REFERENCES}

[1] Zhou Bangyao. Research about the Co-construction and Sharing Framework of Digital Education Resource Base in Higher Vocational College [J]. Vocational Education Research, 2012, (6): 173-175.

[2] Zhang Xiaomei. Research about the Co-construction and Sharing Evaluation Mechanism of Basic Education Resource Region [J].Teaching and Management, 2017, (24): 11-14.

[3] Ding Guizhi. Reflections about the Construction of Sharing Resources for Regional Vocational Education [J]. Higher Vocational Education, 2016, (1): 19-21.

[4] Chen Zhiwei, et al. Analysis on the Construction of Co-construction and Sharing Platform for Regional Basic Education Resources [J]. Straits Science, 2013, (12): 37-38.

[5] Technical Specifications for the Construction of Education Resources [S]. Beijing: the Education Informatization Technology Standard Committee of the Ministry of Education, 2002.

[6] Ke Heping, and Li Chunlin. Research about the Co-construction and Sharing Mechanism of Regional Education Resources Based on Grid Technology [J]. E-education Research, 2008, (1): 63-68.

[7] Yang Jianliang. The Construction of Digital Education Resource Cloud Sharing Service Platform in Regional Universities [J]. Journal of Hunan First Normal College, 2016, (3): 82-85.

[8] Wang Hairong, and Li Weijun. Research about the Regional Sharing Model of Education Resources in Universities [J]. Education Forum, 2017, (8): 72-74. 